\title{
A Study of Over-The-Counter (OTC) Drug Usage Pattern among the Patients attending a Medical College Hospital
}

\author{
Tejasvi.P.K ${ }^{1}$, Magendran.. ${ }^{2}$ \\ ${ }^{1}$ Second year MBBS, ${ }^{2}$ Professor, Department of Forensic Medicine, \\ Saveetha Medical College, Thandalam, Chennai, India
}

\begin{abstract}
Background:Over the counter drug abuse is a growing problem and it needs more recognition. This current study is aimed to assess the pattern of over the counter drug usage among the patients attending Saveetha medical college hospital, Chennai, Tamil Nadu.

Method: This cross-sectional questionnaire based study was conducted at Saveetha medical college and hospital, Chennai, Tamil Nadu. The patients who signed the informed consent form were the study participants, a total of 100 patients were involved. The study period lasted from $23^{\text {rd }}$ January 2019 to $30^{\text {th }}$ March 2019. After the data was obtained they wereanalyzed using Microsoft excel. Percentages and frequency were calculated.

Result: A total of 100 filled questionnaires were collected from the study participants. Majority of the participants (63\%) bought OTC drugs on occasion and the rest (37\%) bought them always. Most of them (43\%) consumed OTC drugs when the symptoms were minor/manageable, $33 \%$ of them whenever they felt sick and $24 \%$ when they couldn't go to a doctor. Many (41\%) believed they could relieve fever by using OTC drugs, $20 \%$ to relieve nausea and 39\% to relieve headache. Antipyretics (47\%) were the most commonly consumed OTC drug. Most (38\%) common reason for choosing OTC drug was to save time.

Conclusion: This study helped gauge the general public's views on OTC drug usage and gives an idea about the amount of work that is yet to be done or has to be done to bring OTC drug abuse under control. It is almost obligatory to make the patients understand the detrimental effects of OTC misuse and abuse- and the most effective way to achieve this is by making the people aware of them in the first place. Even though OTC drug abuse is a largely recognized problem, we still have a long way to go in terms of actually solving it.
\end{abstract}

Keywords: Over the counter drug, OTC drug misuse and abuse, self-medication.

\section{Introduction}

A drug is a substance intended for use in the diagnosis, cure, mitigation, treatment, or prevention of disease.

\section{Corresponding author:}

Magendran. J, MBBS, MD

Professor, Department of Forensic Medicine'

Saveetha Medical College, Thandalam, Chennai, India

Mob:+919841449887, E-mail: drmagi83@yahoo.com
OTC drugs are:

- Drugs that do not require a doctor's prescription

- Bought off-the-shelf in stores

monographs ${ }^{1}$.

Regulated by FDA through OTC drug

OTC drug monographs are a kind of "recipe book" covering acceptable ingredients, doses, formulations and labeling. Monographs will continually be updated adding additional ingredients and labeling as needed. Products conforming to a monograph may be marketed 
without further FDA clearance, while those that do not, must undergo separate review and approval through the "New Drug Approval System"1.2

Simply put, Over the Counter (OTC) drugs are medicines available without a prescription at pharmacies and are a part of self-medication process.

OTC medications have become a mainstay of Indian healthcare as more and more people are self-medicating.

A survey conducted in 2015, participated by 20,000 people from 10 Indian cities through an online doctor consulting platform, found that $52 \%$ of the participants practiced self-medication - citing lack of time to visit a doctor, wanting to save on consultation fee, reliance on internet for solutions as themajor reasons ${ }^{2}$.

Patients rely more on their friendly neighbourhood chemists to give them their appropriate medication for ailments such as cough, cold, allergies, headache, fever and even skin-related conditions ${ }^{2}$.

OTC drugs can provide immediate relief and are safe to an extent but people should realize that even an aspirin has adverse effects or can cause harm. People should realize that OTC medications are intended to treat short term illnesses and symptoms. Many OTC drugs are formulations of several medications which could interact with each other and cause harm. According to the FDA the most vulnerable people i.e. people most at risk are young children, adults over 55 and patients using drugs that affect kidneys.

Globally there is a demarcation - a separate category for drugs that can be sold without a prescription, but India doesn't have one ${ }^{4,5}$. If regulated properly - armed by more patient education, OTC medications can be an useful tool to deal with the problems of rising out-ofpocket healthcare costs, inadequate doctor-patient ratio and, weak and overburdened public healthcare system.

OTC medication abuse is a recognized problem and more research is needed to quantify the problem. This questionnaire based study is aimed to access the pattern of OTC drug usage and make people aware of the risks of self-medication. People shouldconsciously take steps to- go to the doctor, avoid unnecessary selfmedications, adhere to the recommended dosage and read the labeling. Reporting any and all of the adverse effects experienced due to the consumption of an OTC drug ensures that proper pharmacovigilant actions can be taken. Following which the harmful effects of OTC drug usage can be minimized. Bottom line is that we should educate the patient before they self-medicate, so that they can make the right choices.

\section{Materials and Method}

This cross-sectional, questionnaire based study was conducted to assess the pattern of OTC drug usage among the patients attending Saveetha Medical College hospital Chennai. The duration of the study was from $23^{\text {rd }}$ January 2019 to $30^{\text {th }}$ March 2019.

The study was conducted after obtaining permission and approval from the IRB.The participants in the study were the patients who attendedSaveetha Medical college, Thandalam.Objectives and procedure of the study were explained to the participants and those who signed the informed consent form were enrolled in the study. Those who hesitated to participate were excluded from the study.

The questionnaire containing various questions regarding OTC drug usage, like place of purchase of OTC drug, frequency of buying OTC drugs, common reason for consuming OTC drug etc was administered to each participant. The filled questionnaires were then retrieved from 100 participants.

Statistical tool: All the data obtained were analyzed through Microsoft excel. Percentages were calculated and chi-square test was done.

\section{Result}

\section{Gender:}

Both women and men who took part in the survey were equally likely to use OTC medications.

\section{Place of purchase of OTC drugs:}

It was observed that $49 \%$ of the participants purchased OTC drugs from outside pharmacies, while $33 \%$ got them from hospital pharmacies and $18 \%$ got them from friends or relatives.

\section{Frequency of buying OTC medications:}

$63 \%$ of the participants bought OTC drugs on 
occasion while $37 \%$ of the participants opted to buy OTC drugs always.

Figure 1: Time of consumption of OTC drugs

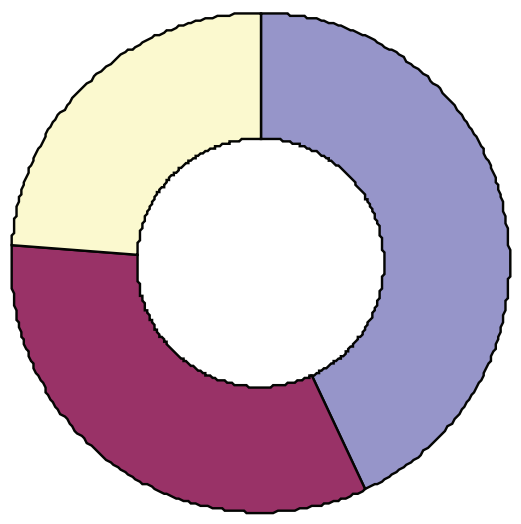

a Minor/Manageable Symptoms

$\square$ Whenever Sick

$\square$ Can't go to a Doctor

$43 \%$ of the participants consumed OTC drugs when the symptoms were minor or manageable, $33 \%$ whenever they felt sick and $24 \%$ when they couldn't go to a doctor (Figure 1)

Figure 2: Most common reason for purchase of OTC drugs

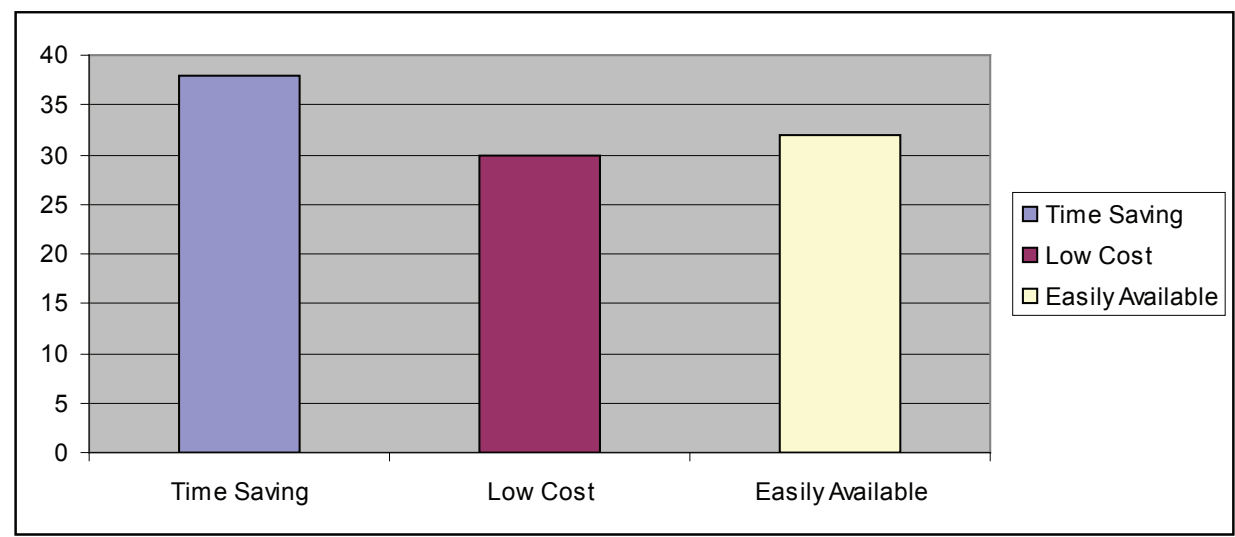

$38 \%$ of the participants cited time saving as the reason for using OTC drugs, $30 \%$ of the participants used OTC drugs as they were a cheaper option and $32 \%$ used OTC drugs as they were easily available (Figure 2)

Figure 3: Most common OTC drug consumed

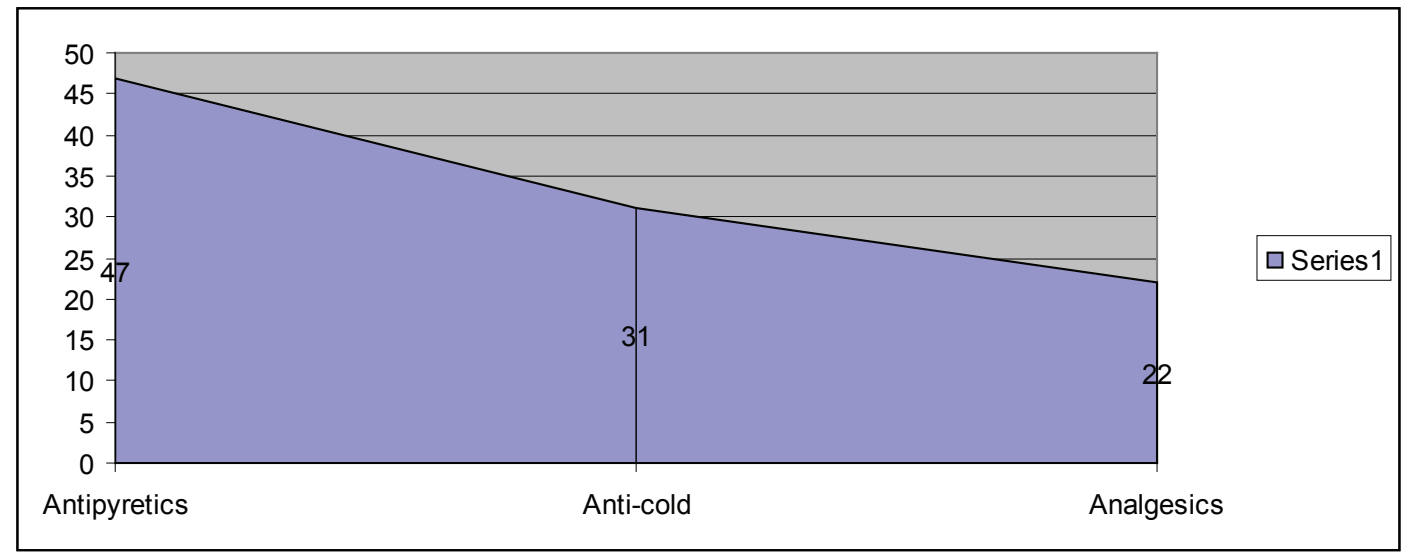

$47 \%$ of the participants bought antipyretics the most, $31 \%$ bought anti-cold and $22 \%$ bought analgesics (Figure 3 ) 
Figure 4: Most common ailment they consume OTC drug for

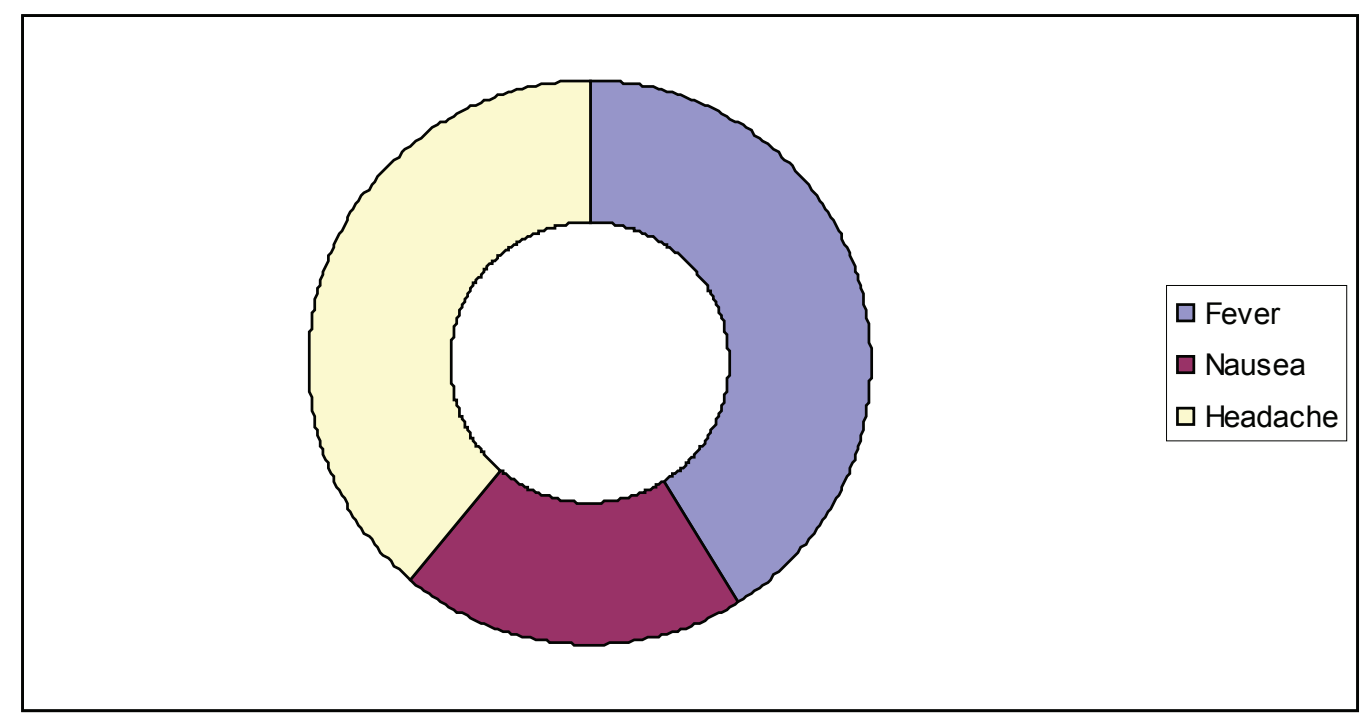

$41 \%$ of the participants took OTC drugs because of fever, $20 \%$ to relieve nausea and $39 \%$ to relieve headache (Figure 4)

TABLE 1: Taking the recommended dose

\begin{tabular}{|l|l|}
\hline Options & Percentage \\
\hline Took more than the recommended dose & $23 \%$ \\
\hline Took only the recommended dose & $77 \%$ \\
\hline
\end{tabular}

On asking whether they took more than the recommended dosage of the OTC drug, $23 \%$ of the participants agreed to over medicating and $77 \%$ of the participants said they only took the recommended dosage even if they weren't relieved of their symptoms or problem.

TABLE 2: Adverse effect because of the OTC drug

\begin{tabular}{|l|l|}
\hline Options & Percentage \\
\hline Has experienced adverse effect & $28 \%$ \\
\hline Has not experienced any adverse effect & $72 \%$ \\
\hline
\end{tabular}

$28 \%$ of the participants had experienced an adverse effect from taking the OTC drug while $72 \%$ of the participants

had not experienced any adverse effect.

\section{Discussion}

The frequency of usage of OTC medications in developing countries is believed to show an increase $e^{6,7}$.There are various studies that suggest that sociodemographic factor plays an important role in OTC drug consumption. Socioeconomic factor also affects theconsumption of OTC drug in a particular demographic area $^{8}$. In our country there are no specific regulations or rules laid down yet that can help bring down OTC medication misuse and abuse ${ }^{2}$.Abusing OTC drugs can lead to a variety of health problem ranging from gastric ulcers to kidney failure and death ${ }^{3}$. It could worsen the condition of the patient by causing other debilitating diseases or making the disease itself to progress. There 
have been many studies before with similar intentions and tones as this one; to raise awareness about the illeffects of OTC drug abuse.

Inthe study done by Parikh.D, Sattigeri.B.M, Kumar.A, Brahmbhatt.S, $87 \%$ of the participants shared OTC drugs among their friends and relatives ${ }^{10}$. In this study however only $18 \%$ percentage of the participantsreceived OTC drugs from friends or relatives.

Easy availability of OTC drugs, chance to avoid the doctor's consultation fee, and save time were among the most common reasons for choosing to buy OTC drugs instead of directly consulting a doctor. As observed by this study, the most common reason for purchase of OTC drugs was to save time (38\%) but in the study done byMourya, A., Mary, C., James, C., Jose, J., \& Srinivasan the most common reason was easy accessibility.

In this study, it was found that majority of the participants took OTC drugs as a remedy for fever (41\%). While in the study done by Parikh.D, Sattigeri.B.M, Kumar.A, Brahmbhatt.S the frequently reported illnesses that prompted self-medication were headache, cough and cold ${ }^{10}$.

In another study ${ }^{13}$, the most common drug used for self-medicating was paracetamol, this is in line with the current study, according to which antipyretics (47\%) were most commonly consumed by the participants.

Another study, from the Journal of Public done by Niamh AFingleton, Margaret C Watson, Eilidh M Duncan, came to the conclusion that analgesics were the drugs commonly misused or abused (dependence was reported) and the most common illnesses were cough and cold ${ }^{14}$. This is in contrast with the current study, which gathered that the most common OTC used were antipyretics and the most common illness was fever.

It was found that $28 \%$ of the participants in the current study had experienced adverse reactions from taking OTC drugs, while in a different study $18.62 \%$ of the participants had experienced side effects from consuming OTC drugs ${ }^{16}$.

The variation in the results obtained by all the past studies and this one is probably due to the difference in sociodemographic details of the study.

\section{Conclusion}

OTC medication misuse and abuse is a growing problem, especially in developing countries like ours and it has been overlooked. Raising awareness about the adverse effects of self-medication is the best way to counter this problem. It should be an obligatory part of the duties of a health care professional.

Educating the public or the patients on how to self-medicate is an important step that can be taken to reduce the chances of them misusing or abusing OTC medications. A patient or person solely dependent on themselves or blindly trusting their local pharmacists for the right remedy might end up with a bigger disease or problem than with what they started. They focus on just treating the symptom and might even let the underlying disease progress into a severe or fatal form.

Interventions at different levels (accessibility, affordability) that will change the public's perception of OTC medication usage and vigilance during drug dispensation may help reduce the OTC medication abuse.

\section{Conflict of Interest : Nil}

\section{Source of Funding : Self}

Ethical Clearance : Obtained

\section{References}

1. US Food and Drug Administration.Bringing an over the counter drug to market[online].2011 [updated 2011 December 5].

2. US food and Drug Administration. Drug Applications for Over-the-Counter (OTC) Drugs [online]. 2015 [updated 2015 January 7]. Available fromhttps:/www.fda.gov/drugs/typesapplications/drug-applications-over-counter-otcdrugs

3. Viswanath Pilla. Why India needs a comprehensive policy on OTC drugs [online]. 2018 [updated 2018 October 14]. Available at https://www. moneycontrol.com/news/health-and-fitness/whyindia-needs-a-comprehensive-policy-on-otcdrugs-3043811.html

4. Jeffrey Juergens. Understanding OTC (Over the Counter) drugs [online]. 2019 [updated 2019 February 20]. Available athttps://www. 
addictioncenter.com/drugs/over-the-counter-drugs

5. Prabha Raghavan. India may soon give OTC drugs definition[online]. 2017 [updated 2017 September 20].

6. Panda A, Pradhan S, Mohapatro G, Kshatri JS. Predictors of over-the-counter medication: A crosssectional Indian study. PerspectClin Res 2017;8:7984

7. Shankar PR, Partha P, Shenoy N. Self-medication and non-doctor prescription practices in Pokhara Valley, Western Nepal: A questionnaire-based study. BMC Fam Pract 2002;3:17.

8. Figueiras A, Caamaño F, Gestal-Otero JJ. Sociodemographic factors related to self-medication in Spain. Eur J Epidemiol 2000;16:19-26.

9. Jain S, Upadhyaya P, Goyal J, Abhijit K, Jain P, Seth V, Moghe VV. A systematic review of prescription pattern monitoring studies and their effectiveness in promoting rational use of medicines. Perspect Clin Res [serial online] 2015 [cited 2019 Aug 13];6:8690. Available from: http://www.picronline.org/ text.asp?2015/6/2/86/154005

10. Parikh D, Sattigeri BM, Kumar A, Brahmbhatt S. A survey study on use of over the counter (OTC) drugs among medical students, nursing and clerical staff of a tertiary care teaching rural hospital. Int $\mathbf{J}$ Res Med Sci 2013;1:83-6.

11. Caamano, F., Fgueiras, A., LadoLema E, and
Gestalo-Otero, J.J. Self-medication: Concept and "User" Profile. Gac Santi 2000;14:294-99.

12. Hankar PR, Partha P, Shenoy N. Self-Medication and non-doctor prescription practices in Pokhara valley. Western Nepal: MC Family Practice 2002;3:17.

13. Kumar V, Mangal A, Yadav G, Raut D, Singh S. Prevalence and pattern of self-medication practices in an urban area of Delhi, India. Med J DY Patil Univ [serial online] 2015 [cited 2019 Aug 13];8:1620. Available from: http://www.mjdrdypu.org/text. asp?2015/8/1/16/148828

14. Niamh A. Fingleton, Margaret C. Watson, Eilidh M. Duncan, Catriona Matheson, Non-prescription medicine misuse, abuse and dependence: a crosssectional survey of the UK general population, Journal of Public Health, Volume 38, Issue 4, December 2016, Pages 722-730, https://doi. org/10.1093/pubmed/fdv204

15. Patel PD, Patel KP, Malhotra SD. Survey of use of over the counter drug and other than over the counter drugs among medical students, nursing and technician staff of a tertiary care teaching hospital. Int J Basic Clin Pharmacol 2017;6:592-6.

16. Mourya, A., Mary, C., James, C., Jose, J., \& Srinivasan, R. (2019). A Survey on Over The Counter Drug usage in the Community. Journal of Drug Delivery and Therapeutics, 9(2-s), 406-416. https://doi.org/10.22270/jddt.v9i2-s.2538 